München. Das Staatsexamen legte er 1901 in Bern ab; nach Studienaufenthalten in Wien und Paris verfaßte er als Assistent bei Prof. Girard seine Dissertation über das Thema: «Musik und Narkose», die ihm den Doktortitel einbrachte. Eine weitere Assistentenzeit brachte er im Berner Frauenspital bei Prof. Peter Müller zu; 1907 ließ er sich in Bern als Arzt und Geburtshelfer nieder. 1908 wurde er Badearzt in Yverdon, eine Beschäftigung, die ihn infolge der dortigen Kurpraxis auf das Gebiet der Oto-Phino-Laryngologie führte. Nach Bern zurückgekehrt, widmete er sich ausschließlich diesem Spezialgebiet und war in der Folge bis 1922 Gehülfe und Vertreter von Prof. Lüscher sen. auf der poliklinischen Abteilung. 1914 habilitierte sich v. Rodt, der nie den Kontakt mit geschichtlichen Fragen verloren hatte, in Bern für Geschichte der Medizin: Dieses Fach wurde vorher in Bern nicht gelesen; die Zuhörer waren nicht gerade zahlreich; v. Rodt, der mit seinem ganzen Wesen in bernischen Verhältnissen fußte, las speziell über bernische Geschichte der Medizin.

1917/18 unterbrach ein Aufenthalt in Österreich seine Tätigkeit in Bern; er hatte die Aufgabe mit Minister v. Planta übernommen, die österreichischen Gefangenenlager zu inspizieren. - Sein Gesundheitszustand, arthritische Beschwerden, machte später jährliche Kuraufenthalte in Italien nötig; dies setzte ihn in Stand, die ältere italienische Kunst, die ihm aus dem Schrifttum wohl bekannt war, aus eigener Anschauung genauer kennen zu lernen. Seine Neigung zu heraldischen Studien benützte er u. a. um das Wappen des Berner Burgerspitales («zum Heiligen Geist»), dessen Direktion er als Nachfolger seines Vaters lange angehörte, durch Studien in Rom, wo das Original des Ritterkreuzes des Ordens vom Heiligen Geist sich befindet, richtig zu stellen; dieses Kreuz, das ein Quartier des Wappens einnimmt, war im Laufe der Zeiten durch Unkenntnis falsch geformt worden. Das mit der Geschichte eng verbundene Gebiet der Genealogie wie das der Heraldik, zog ihn stark an; seiner Feder verdanken wir eine Reihe von Artikeln im Schweiz. Geschlechterbuch. Auch war er ein tätiges Mitglied des historischen Vereins der Stadt Bern.

Als 1921 auf Initiative von H. Sigerist die Schweizerische Gesellschaft für Geschichte der Medizin und der Naturwissenschaften gegründet wurde, war v. Rodt mit ganzem Herzen dabei. Er hätte auch später wohl den Vorsitz übernehmen sollen, wenn ihm dies nicht durch seine schwankende Gesundheit verunmöglicht worden wäre. Er blieb aber mit seinem vollen Interesse mit der Gesellschaft verbunden und besuchte die Jahresversammlungen so oft es ihm möglich war. Aus seinen eigenen Arbeiten machte er nie viel Wesens; v. Rodt war eine bescheidene Natur und drängte sich nicht vor. Alle die ihn kannten, schätzten sein freundliches Wesen und seine Dienstfertigkeit; die Schätze seiner Büchersammlung teilte er jedem, der sie benützen wollte, bereitwillig mit.

Seit etwa zwei Jahren verschlechterte sich seine Gesundheit. Erst anfangs Dezember 1944 wurde er bettlägerig und nach etwa drei Wochen eines mühsamen, aber schmerzlosen Krankenlagers kam das Ende.

R. v. Fellenberg.

\title{
Arbeiten von Dr. v. Rodt:
}

1. Musik und Narkose. Diss. Bern 1903 bei Stämpfli \& Cie.

2. Mitarbeit an der Geschichte der Medizinisch-Chirurgischen Gesellschaft des Kantons Bern von Prof. Lindt. Bern 19..

3. Beitrag zur Geschichte der Schilddrüse. Deutsche Zeitschr. f. Chirurgie Bd. 116, 1912. 
4. Aus dem Leben des Wilhelm Fabricius Hildanus. Schweiz. Medizin. Wochenschr. 1934, Nr. 23, S. 540.

4a. Habilitationsschrift über Lionardo da Vinci 1914 (wurde vielleicht in der wirren Zeit des Anfanges des ersten Weltkrieges gar nicht gedruckt; auf der Berner Hochschulbibliothek unauffindbar).

5. Artikel v. Mülinen im Schweizerischen Geschlechterbuch Bd. V.

6. Ebenso Art. v. Rodt im Schweizerischen Geschlechterbuch Bd. II und Bd. VI.

7. Mitarbeit an der noch nicht beendeten Geschichte des Berner Burgerspitals von Dr. Morgenthaler, die in absehbarer Zeit herauskommen soll.

Die übrigen Veröffentlichungen v. Rodts sind otologischer Art und interessieren hier weniger. Vorträge und Arbeiten aus der bernischen Geschichte wurden meist nicht veröffentlicht. 